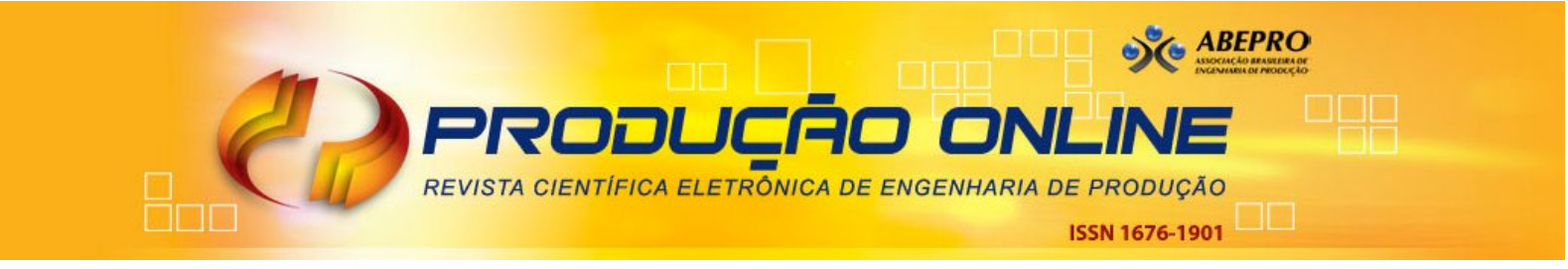

\title{
UMA PROPOSTA DE ESTRUTURA E UTILIZAÇÃO DO GERENCIAMENTO DE PROCESSOS DE NEGÓCIO (BPM)
}

\section{A PROPOSAL OF BUSINESS PROCESSES MANAGEMENT (BPM) STRUCTURE AND USE}

\author{
Rafael Araujo Kluska* E-mail: rafael@kluska.com.br \\ Edson Pinheiro de Lima* e** E-mail: e.pinheiro@pucpr.br \\ Sérgio Eduardo Gouvêa da Costa* e ** E-mail: s.gouvea@pucpr.br \\ *Pontifícia Universidade Católica do Paraná (PUCPR), Curitiba, PR, Brasil \\ **Universidade Tecnológica Federal do Paraná (UTFPR), Curitiba, PR, Brasil
}

\begin{abstract}
Resumo: Os Processos organizacionais, também chamados de processos de negócio, tornaram-se estruturas fundamentais para o gerenciamento das organizações modernas. Segundo alguns autores, conhecer o fluxo de trabalho das organizações é uma condição necessária para o desenvolvimento de processos de melhoria contínua. São evidentes os benefícios e vantagens proporcionados pela utilização de uma abordagem fundamentada no gerenciamento de processos BPM (Business Process Management). Dentre os benefícios, são apontados ganhos de eficiência, qualidade e flexibilidade, além de outros aspectos para que se criem vantagens competitivas sustentáveis. Há na literatura de BPM estudos abrangentes sobre o tema, no qual pode-se observar diversas definições e elementos que caracterizam as diferentes aplicações. O objetivo deste artigo é propor um framework conceitual de interligação entre os elementos BPM, buscando um melhor entendimento sobre os processos organizacionais e atuação no ambiente da gestão organizacional. São realizados estudos exploratórios de identificação e classificação de elementos BPM. Para analisar as interligações entre eles realizou-se uma revisão da literatura e desenvolveu-se um estudo sobre a utilização profissional do BPM. Como resultados é apresentado um conjunto de elementos BPM na forma de: metodologias, técnicas e ferramentas que compõem ou possam ser ligados de forma funcional à estrutura conceitual do BPM. Com esta pesquisa é possível afirmar que os resultados da aplicação do BPM não se limitam à busca do aumento de eficiência operacional, podendo também ser considerado elemento chave de suporte à gestão organizacional.
\end{abstract}

Palavras-chave: BPM. Gerenciamento de Processos de Negócio. Modelagem de Processos. Processos Organizacionais.

Abstract: The organizational processes, also known as business processes, have became a fundamental structure for the management of the modern organizations. Knowing the work flow of the organization is a necessary condition for the development of continuous improvement processes. The benefits and advantages provided by the use of an approach based on BPM (Business Processes Management) are evident. The benefits include improvements in efficiency, quality and flexibility, besides other aspects generating sustainable competitive advantages. There is a wide range of studies on BPM, which display several definitions and elements characterizing the various applications. This work aims to propose a conceptual framework for interconnection between BPM elements, thus providing a better understanding of organizational processes and performance in organizational management environment. As a result, a group of BPM elements is identified and classified in: methodologies, techniques and tools which are a part of or can be efficiently connected to BPM conceptual structure. A framework for conceptual interconnection between those elements is also provided. The results of BPM application are not limited to the search for operational efficiency, but might also be considered as an element to support the organizational management. 
Keywords: BPM. Business Processes Management. Organizational Processes. Processes Modeling.

\section{INTRODUÇÃO}

Os Processos organizacionais, também conhecidos como processos de negócio, tornaram-se estruturas fundamentais para o gerenciamento das organizações modernas (CAMPOS, 2013). Nas últimas décadas, este conhecimento ganhou grande popularidade e ampla disseminação (ALBUQUERQUE, 2012). Segundo Gonçalves (2000), "Não existe um produto ou serviço oferecido por uma empresa sem um processo empresarial". Dessa forma, conhecer o fluxo de trabalho operacional tornou-se condição necessária para o desenvolvimento de produtos e serviços.

Cada vez mais os responsáveis de áreas como: $\mathrm{RH}$; $\mathrm{TI}$ e Administração em geral, apresentam crescente interesse pelos processos organizacionais (CAMPOS, 2013). Também pode-se acompanhar esse interesse no meio acadêmico devido ao grande número de publicações e artigos com o foco nesta temática (SANTOS ROCHA E FANTINATO, 2013).

Para alguns pesquisadores, uma vantagem da abordagem por processos consiste na capacidade deles transporem de forma horizontal as estruturas funcionais das organizações (ABPMP, 2014; CLARK E WHEELWRITHG, 1992). Sob esta perspectiva, os processos transcendem as diferentes áreas de uma organização com o objetivo de criar fluxos fim a fim (ALBUQUERQUE, 2012; GONÇALVES, 2000; MELÃO E PIDD, 2000; SELTSIKAS, 1999). Dessa forma, proporcionando otimização e controle sobre as operações (ABPMP, 2014).

Empresas de grande porte e representatividade como: IBM, Unisys, Oracle, SAP e IDS Sheer, apresentam soluções dedicadas ao gerenciamento e operacionalização de processos. Essas ferramentas são conhecidas como soluções BPMS (BPMS - Business Process Management Suite) (ABPMP, 2014; CAMPOS, 2013; MAUREEN FLEMING E SILVERSTEIN, 2011; SCHULTE, HILL E JONES, 2012). Neste mercado também pode-se observar a atuação da empresa BONITA SOFT com o projeto open source, Bonita Open Solution ("Bonitasoft - Open Source Workflow \& BPM software," [s.d.]).

No relatório "IDC MarketScape: Worldwide Business Process Platforms 2011 Vendor Analysis", desenvolvido pela consultoria IDC Study, é realizada uma Revista Produção Online, Florianópolis, SC, v.15, n. 3, p. 886-913, jul./set. 2015. 
avaliação dos fornecedores de soluções BPMS. Segundo o relatório, a Oracle foi reconhecida como líder de mercado por distribuir uma ferramenta com funcionalidades aprimoradas, interface sofisticada, funções empresariais na camada de processos e recursos de execução de negócios (MAUREEN FLEMING E SILVERSTEIN, 2011).

Em 2012 o relatório "Magic Quadrant for Intelligent Business Process Management Suites" (SCHULTE, HILL E JONES, 2012), publicado pela empresa de consultoria Gartner, apresenta um quadrante composto por treze fornecedores de soluções BPM. Nesta publicação é possível validar a composição do ranking das soluções BPMS, sendo destacada a participação da empresa Bonita Soft no mercado BPMS.

Em meio ao universo de gerenciamento de processos de negócio (BPM), o BPM DAY, realizado pela ABPMP Brasil, é reconhecido como o maior evento de BPM do mundo. Ele conta com mais de 15.300 participantes, desde sua primeira edição em maio de 2011. Esse evento objetiva ser um dia exclusivamente dedicado à discussão de assuntos relacionados ao BPM. Com apresentações de casos reais de aplicação prática do BPM, desenvolvidos em organizações públicas e privadas (“ABPMP Brasil," [s.d.]).

O objetivo deste trabalho é proporcionar uma visão do universo BPM. Compilando e organizando os elementos BPM, busca-se analisar as possíveis interligações existentes entre eles, proporcionando assim, um melhor entendimento horizontal sobre esse conhecimento. Para isso, realizou-se uma revisão da literatura pertinente e desenvolve-se um estudo sobre a utilização profissional do BPM. Esses esforços foram divididos em três etapas: Levantamento e exploração da literatura; Levantamento e identificação das soluções BPM comerciais; Conceituação e definição dos elementos BPM.

Como resultado é apresentado um conjunto de elementos BPM na forma de: metodologias, técnicas e ferramentas, que compõem ou possam ser ligados de forma funcional à estrutura conceitual do BPM. Também é apresentado um framework conceitual de interligação entre estes elementos.

\section{PROJETO DA PESQUISA}


O BPM já apresenta um histórico consolidado por meio de publicações e aplicações comerciais. Devido a este fato, é possível que, por meio do seu estudo, obtenha-se uma visão parcial sobre suas especificidades. Esta pesquisa objetiva estudar o BPM partindo de alguns conceitos gerais sobre seus principais elementos, de forma a compor uma visão desse universo.

Com o uso de uma abordagem investigativa, busca-se compreender conceitos, aplicações e interligações dos elementos BPM. Para isso, de forma estratégica, foram desenvolvidos estudos e levantamentos sobre a literatura pertinente ao BPM, assim como sobre suas aplicações comerciais.

A busca por esse conhecimento foi organizada com o auxílio de um projeto para a pesquisa. Este projeto seguiu recomendações do reconhecido Guia de Gerenciamento de Projetos PMBoK (PMI, 2008). Assim como sugere o guia, as atividades do projeto foram organizadas conforme o ciclo de vida de um projeto.

\footnotetext{
O ciclo de vida de um projeto consiste nas fases do mesmo que geralmente são sequenciais e que às vezes se sobrepõem, cujo nome e número são determinados pelas necessidades de gerenciamento e controle da(s) organização(ões) envolvidas, a natureza do projeto em si e sua área de aplicação. (PMBOK, 2009, P. 21).
}

As fases do ciclo de vida de um projeto são: Início do projeto; Organização e preparação; Execução do trabalho do projeto e Encerramento do projeto. Elas permitem mapear qualquer tipo de projeto, independentemente do tamanho e/ou complexidade (PMI, 2008).

A Figura 1 representa o projeto da pesquisa que compreende todas as fases do gerenciamento do ciclo de vida do projeto e as relações entre as atividades.

Figura 1 - Projeto da Pesquisa 


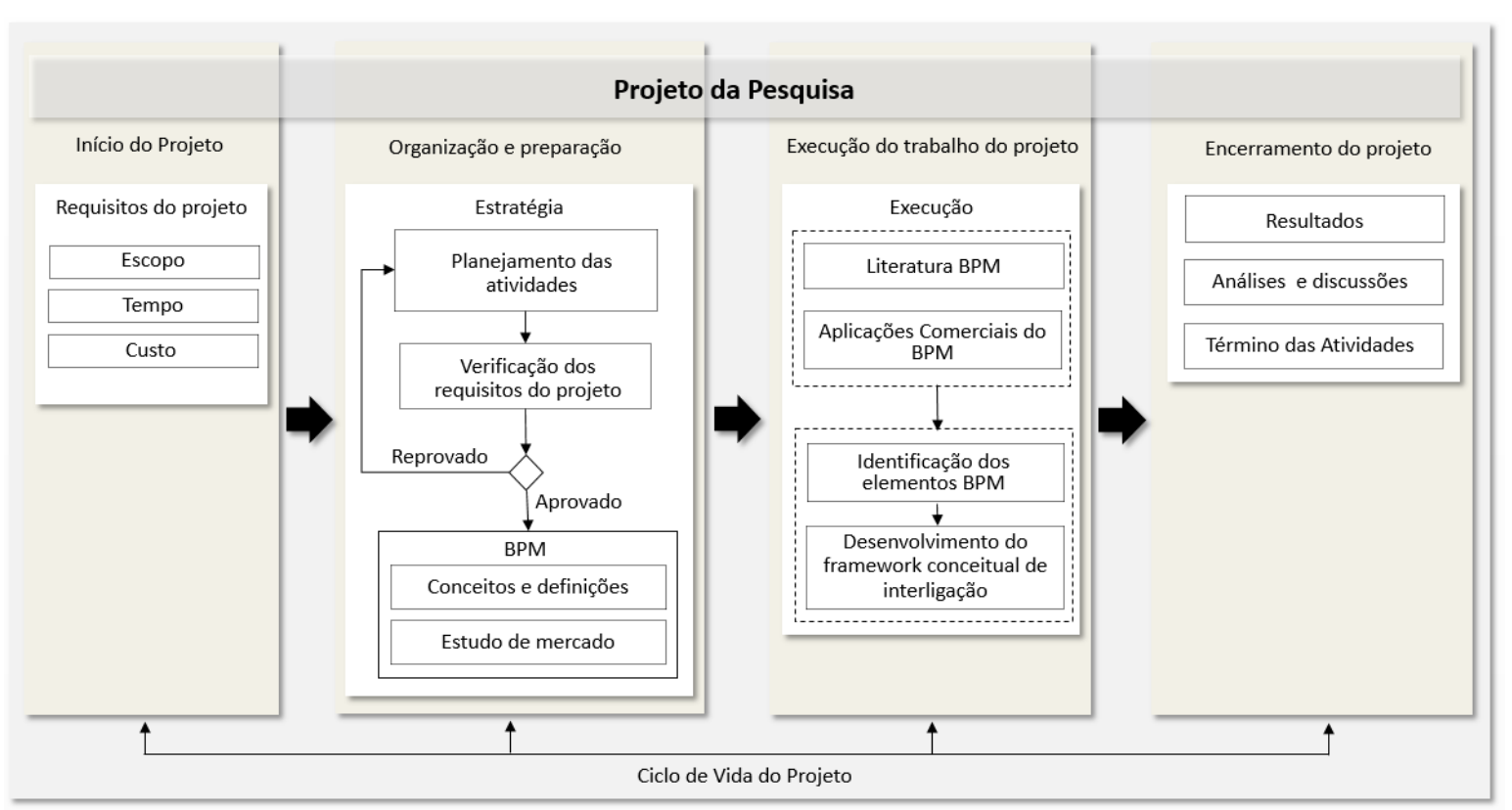

Fonte: O autor (2014)

Cada fase do ciclo de vida é composta por um grupo de atividades que, quando realizadas, são compreendidas como o desenvolvimento do projeto. $\mathrm{Na}$ sequência, é apresentado um descritivo sobre o desenvolvimento de cada fase do projeto:

a) Início do Projeto - Para este projeto foi determinado como escopo o desenvolvimento um framework conceitual de interligação entre os elementos BPM, buscando um melhor entendimento sobre os processos organizacionais e sua atuação no ambiente da gestão organizacional. Esse trabalho, de maneira prática, deve proporcionar uma visão sobre 0 universo BPM. O tempo dedicado para o desenvolvimento deste projeto foi de aproximadamente dois anos, com início em 2012 e término em 2014. Os custos associados a execução do projeto estão vinculados à aquisição de matérias e publicações pertinentes ao tema BPM;

b) Organização e preparação - Nesta fase, foi desenvolvido o planejamento das atividades do projeto. Durante o planejamento, identificou-se um inerente comportamento cíclico de verificação dos requisitos do projeto. Essa característica foi interpretada na forma de um mecanismo estratégico de validação do alinhamento entre as atividades planejadas e o escopo do projeto. Após a aprovação do planejamento, obteve-se um conjunto de atividades dispostas em dois grupos: um de atividades voltadas à revisão de literatura e outro para o estudo do mercado das soluções BPM; Revista Produção Online, Florianópolis, SC, v.15, n. 3, p. 886-913, jul./set. 2015. 
c) Execução do trabalho do projeto - As atividades foram executadas de forma paralela. Com isso, o conhecimento foi construído interativamente. As setas na Figura 8, localizadas no campo de execução do trabalho do projeto, representam uma relação de causa-efeito entre as duas frentes investigadas. Essa relação busca representar a sequência de execução do trabalho;

d) Encerramento do projeto - Após a conclusão das atividades de execução do trabalho, considerou-se a fase de encerramento do projeto. Como resultado, é apresentado um conjunto de elementos BPM na forma de: metodologias, técnicas e ferramentas que compõem ou possam ser ligados de forma funcional à estrutura conceitual do BPM. Também é apresentado um framework conceitual de interligação entre os elementos. Com isso, foram desenvolvidas análises e discussões sobre os resultados.

\section{REVISÃO DE LITERATURA}

O objetivo de desenvolver uma revisão de literatura sobre o BPM é conhecer e compreender melhor este universo. Sabe-se que as fronteiras e os conceitos deste conhecimento não se limitam exclusivamente, a uma única fonte de informação. Logo, para compreender este universo, foram necessárias pesquisas em diversas publicações.

\subsection{Visão do Universo BPM}

Com o objetivo de promover uma visão do universo BPM, buscou-se levantar junto à literatura pertinente os conceitos e definições sobre seus elementos. Dentre as obras escolhidas estão composições de grande representatividade, como o Guia BPM CBOK (ABPMP, 2014) e outros clássicos dessa literatura.

Durante o levantamento foi possível dividir o universo BPM em três grupos de conhecimento: Gerenciamento de processos de negócio, Modelagem de Processos de Negócio e Automação de Processo de Negócio, demonstrados na Figura 2.

Figura 2 - Visão do Universo BPM 


\section{Visão do Universo BPM}

Gerenciamento de processos de negócio

$\checkmark$ Gestão

$\checkmark$ Governança

$\checkmark$ Centro de excelência em processos

$\checkmark$ Modelo de maturidade BPMM inspirado no CMMI

$\checkmark$ Diretrizes para a implantação do BPM
Modelagem de Processos de Negócio

$\checkmark$ Desenho de processos

$\checkmark$ Modelagem de processos de negócio

$\checkmark$ Análise de processos de negócio

$\checkmark$ Gerenciamento de desempenho processos de negócio

$\checkmark$ Gerenciamento do processo
Automação de Processos de Negócio

$\checkmark$ BPMS

$\checkmark$ BM Softwares

$\checkmark$ Sistemas legados

$\checkmark$ SOA-Arquitetura orientada a serviços

Fonte: O autor (2014)

A classificação apresentada visa proporcionar uma visão sobre o que é o BPM. Essa representação foi construída após a conclusão dos estudos sobre o tema. Cada grupo representa um conjunto de conhecimentos específicos sobre o BPM, eles foram selecionados por serem considerados elementos-chave deste conjunto de conhecimento.

No grupo de Gerenciamento de processos de negócio pode-se observar uma atuação mais proativa para a aplicação do BPM junto às competências gerenciais de um negócio. Deste modo, este gerenciamento tem por função coordenar as práticas BPM e organizar todo o trabalho desenvolvido por essa iniciativa (ABPMP, 2014; ZANGISKI, PINHEIRO DE LIMA E GOUVÊA DA COSTA, 2013).

$\mathrm{Na}$ modelagem de processos de negócio, as atividades partem do entendimento do negócio para a construção de um modelo que possa representar os processos deste negócio. Estes modelos devem ser estruturas completas, porém, não devem ser complexas, já que os processos devem ser de fácil interpretação para os seres humanos (ABPMP, 2014; OMG, 2011).

No último grupo, a automação de processos de negócio deve ser considerada mais crítica, já que contém elementos que serão, de fato, trabalhados por colaboradores e apresentados aos clientes. Desta forma, o desenvolvimento desta etapa está diretamente condicionado às outras duas antecessoras, com isso, devese atentar para o correto entendimento de todas as partes de um processo de negócio antes de iniciar esta etapa. Este é um grupo para a escolha da tecnologia, por isso, deve-se estudar as possibilidades de automação e compreender qual 
mecanismo melhor se encaixa nas rotinas operacionais do processo (ABPMP, 2014; CAMPOS, 2013; GOU ET AL., 2003; PENG, SCHROEDER E SHAH, 2012).

\subsection{Publicações Selecionadas}

A escolha das publicações deve-se aos seguintes fatores: Representatividade no meio acadêmico e profissional; Abordagem pertinente de assuntos ligados diretamente ao BPM e Utilização do BPM em aplicações práticas. No Quadro 1 estão listadas as publicações exploradas.

Quadro 1 - Literatura BPM explorada

\begin{tabular}{|l|l|}
\multicolumn{1}{|c|}{ Publicação } & \multicolumn{1}{c|}{ Referência } \\
\hline $\begin{array}{l}\text { Análise e Modelagem de Processos de Negócios } \\
\text { Foco na notação BPMN (Business Process Modeling } \\
\text { Notation) }\end{array}$ & (SOUSA et al., 2013) \\
\hline BPM CBOK Versão 3.0 & (ABPMP, 2014) \\
\hline $\begin{array}{l}\text { BPM \& BPMS: Business Process Management e } \\
\text { Business Process Management Systems }\end{array}$ & (CRUZ, 2010) \\
\hline $\begin{array}{l}\text { Gerenciamento de processos de negócio: BPM - } \\
\text { Business Process Management }\end{array}$ & (BALDAM et al., 2007) \\
\hline Gestão de processo voltada para resultados & $\begin{array}{l}\text { (PALVARINI E QUEZADO, } \\
\text { 2013) }\end{array}$ \\
\hline $\begin{array}{l}\text { Mapeamento e gestão por processos BPM, Gestão } \\
\text { orientada à ENTREGA por meio de OBJETOS } \\
\text { METODOLOGIA GRAUSS }\end{array}$ & (PAVANI JÚNIOR E \\
\hline $\begin{array}{l}\text { Metodologia de Pesquisa em Engenharia de produção } \\
\text { - Capítulo 9, Processos: Uma abordagem da } \\
\text { Engenharia para a Gestão de operações }\end{array}$ & (PINHEIRO DE LIMA E \\
\hline Modelagem de processos com BPMN & GOUVÊA DA COSTA, 2012) \\
\hline $\begin{array}{l}\text { Modelagem Empresarial - Ferramentas para a } \\
\text { tomada de decisão }\end{array}$ & (CAMPOS, 2013) \\
\hline The Basics of Process Mapping & (PIDD, 1996) \\
\hline $\begin{array}{l}\text { Real-Life BPMN: Using BPMN 2.0 to Analysze, } \\
\text { Improve, and Automate Process in Your Company }\end{array}$ & (DREUND AND RÜCKER, 2012) \\
\hline
\end{tabular}

Fonte: O autor (2014)

A partir deste conjunto de publicações gerou-se uma biblioteca de conhecimentos BPM. Ela é utilizada para compreender melhor os conceitos e definições dos elementos deste universo. 


\title{
3.3 BPM Conceitos e definições
}

Com a biblioteca BPM criada, foram levantados conceitos e definições sobre este tema. O objetivo é esclarecer e proporcionar o entendimento sobre o BPM. Este conjunto de conhecimento "representa uma nova forma de visualização estratégica das organizações" (ABPMP, 2014). De modo que ele apresenta evidentes benefícios e vantagens em sua utilização.

Com foco em uma abordagem de melhoria contínua, o BPM resulta em ganhos de eficiência, qualidade, flexibilidade, e, além de ser um esforço, proporciona clara vantagem competitiva ao longo do tempo, garantindo a sustentabilidade do negócio (AL-TABBAA, GADD E ANKRAH, 2013; NADARAJAH E KADIR, 2014).

Conforme o Guia BPM CBOK:

\begin{abstract}
Gerenciamento de processos de negócios, BPM (Business Process Management) é uma disciplina gerencial que integra estratégias e objetivos de uma organização com expectativas e necessidades de clientes, por meio do foco em processos ponta a ponta. BPM engloba estratégias, objetivos, cultura, estruturas organizacionais, papéis, políticas, métodos e tecnologias para analisar, desenhar, implementar e gerenciar o desempenho, transformar e estabelecer a governança de processos. (ABPMP, 2014).
\end{abstract}

Em Clark e Wheelwrithg (1992), Gou et al. (2003), Harrison (1998) e Nadarajah e Kadir (2014), é destacada a dificuldade de integração entre os departamentos das organizações. A falta de engajamento entre os departamentos torna-se um empecilho para a obtenção de um processo produtivo efetivo.

$\mathrm{Na}$ Figura 3, utilizada por Sousa et al. (2013) para representar a visão departamental versus visão de processos, é possível observar a disposição e a atuação dos processos, ilustrando a estrutura interfuncional apresentada pelo Guia CBOK (ABPMP, 2014). 
Figura 3 - Visão departamental X Visão por processos

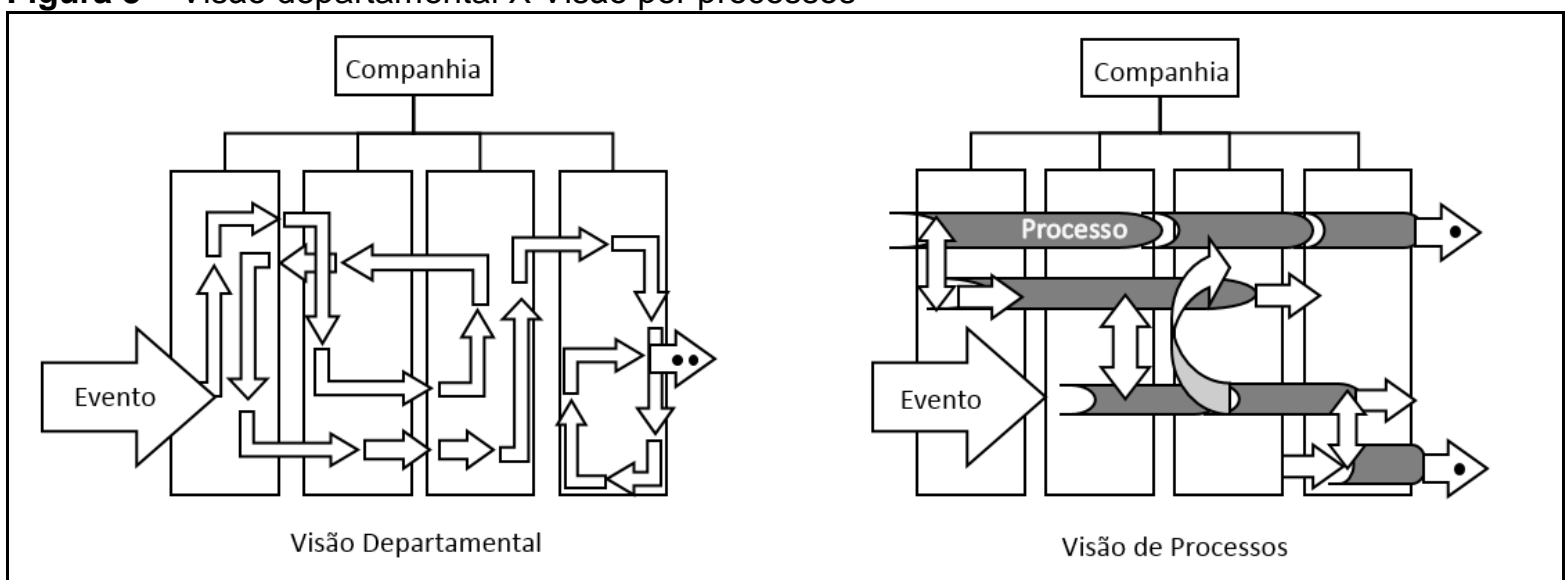

Fonte: Adaptado de Malamut (2005)

Para Pavani Júnior e Scucuglia (2011), a adoção plena de uma estrutura orientada por processos necessita de um período de amadurecimento e transição. Eles apontam alterações na cultura organizacional como fator-chave para a mudança de foco. A Figura 4 ilustra as mudanças ocorridas durante 0 amadurecimento de uma gestão tradicional - Vertical, para a gestão por processos Horizontal.

Figura 4 - Representação da transformação do modelo de gestão funcional para uma estrutura com orientação por processos

$\begin{aligned} & \text { Fertical } \\ & \text { funcional } \\ & \text { processos em } \\ & \text { segundo plano }\end{aligned}$
$\begin{aligned} & \text { Processo com } \\ & \text { funcional em } \\ & \text { segundo plano }\end{aligned}$

Fonte: Paim et al. (2009)

Segundo o Guia CBOK (ABPMP, 2014), o BPM representa uma nova forma de enxergar as operações. Com uma abordagem interfuncional, ou seja, entre as Revista Produção Online, Florianópolis, SC, v.15, n. 3, p. 886-913, jul./set. 2015. 
funções ou departamentos de uma organização, esta visão possibilita compreender todo o trabalho requerido para o desenvolvimento de produtos e serviços (ABPMP, 2014).

\section{ESTUDO DO MERCADO BPM}

Visando a compreensão do mercado BPM, foi realizado um estudo sobre os tipos de produtos comercializados com esta denominação. Para isso, foram analisados os portfólios de produtos de empresas participantes do BPM DAY no ano de 2013.

Sabe-se que este mercado não é composto exclusivamente por empresas participantes destes eventos, uma vez que a disciplina do BPM é muito abrangente (ABPMP, 2014). No entanto, é factível que elas representem de alguma forma, um nicho de mercado do BPM. Após o levantamento dos produtos comercializados, foi possível identificar quatro frentes de atuação: Pacotes de Consultoria, Treinamentos, Sistemas BPM e Soluções BPMS.

Os pacotes de consultorias e os treinamentos apresentam variações de conteúdo e duração de uma empresa para outra. Porém, nas Soluções BPMS é possível identificar uma constância no escopo de atuação.

\subsection{Treinamentos e consultorias}

Tanto consultorias quanto treinamentos abordam assuntos parecidos para a aplicação do BPM dentro de organizações. A seguir, estão listados alguns dos nomes utilizados para a aplicação e o ensino desta disciplina dentro das organizações:

- Gerenciamento de processos de negócio BPM

- Formalização de processos

- Implantação da Gestão por processos

- Escritório de processos

- Projetos de modelagem

- Modelagem BPMN

- Certificação CBPP ABPMP

Revista Produção Online, Florianópolis, SC, v.15, n. 3, p. 886-913, jul./set. 2015. 


\subsection{Sistemas BPM}

Este grupo foi identificado na forma de um conjunto de soluções especializadas para controlar e monitorar processos de negócio. Estes sistemas utilizam-se de arquiteturas próprias, não havendo necessariamente um padrão. Porém, é possível identificar alguns elementos comuns, dentre eles: Base de dados; Processos definidos e Interface gráfica - formulários.

No Quadro 2 estão listadas algumas aplicações destes sistemas, dispostas por setor organizacional.

Quadro 2 - Aplicação / Função de sistemas BPM por setor organizacional

\begin{tabular}{|l|l|}
\hline \multicolumn{1}{|c|}{ Setores organizacionais } & \multicolumn{1}{c|}{ Aplicação I Função } \\
\hline Gestão de RH & $\begin{array}{l}\text { Admissão de colaboradores } \\
\text { Desligamento de colaborados }\end{array}$ \\
\hline \multirow{3}{*}{ Qualidade } & $\begin{array}{l}\text { Plano de ação } \\
\text { Registro de não conformidades } \\
\text { Requisição de treinamentos } \\
\text { Requisição de contratos }\end{array}$ \\
\hline Marketing & $\begin{array}{l}\text { Gestão de incidentes } \\
\text { Infraestrutura } \\
\text { Gestão de documentos } \\
\text { Gestão de impressões }\end{array}$ \\
\hline \multirow{2}{*}{ Controladoria } & $\begin{array}{l}\text { Gestão de campanhas } \\
\text { Desenvolvimento de produtos }\end{array}$ \\
\hline Gestão estratégica de desempenho & $\begin{array}{l}\text { Gestão de investimentos } \\
\text { Auditorias } \\
\text { Solicitações de cotação }\end{array}$ \\
\hline
\end{tabular}

Fonte: Adaptado de ABPMP (2014) e Campos (2013)

Estes recursos não limitam-se apenas a ferramentas computacionais e podem ser compreendidos como sistemas organizacionais de controle de fluxo de atividades; mesmo sem a camada tecnológica, ainda são poderosas ferramentas de gestão e controle operacional. 


\subsection{Soluções BPMS}

Estas soluções são consideradas uma nova categoria de software de gerenciamento (CRUZ, 2013). Elas mudaram a forma como as empresas interagem com departamentos e parceiros de negócio (CAMPOS, 2013; CRUZ, 2010). Conforme Cruz (2010), um BPMS integra, em tempo real, clientes, fornecedores, colaboradores, ferramentas e qualquer elemento que tenha participação em um Processo de Negócio.

É comum encontrarmos duas formas de representação do acrônimo BPMS, sendo em alguns casos reconhecido como Business Process Management Systems (CRUZ, 2010), e outras vezes como Business Process Management Suites (ABPMP, 2014). Neste trabalho será adotado o sufixo Suite, por entender que esta terminologia representa de forma mais heterogênea os componentes que integram as soluções BPMS.

No estudo "Magic Quadrant for Intelligent Business Process Management Suites", apresentado pela consultoria especializada Gartner (SCHULTE, HILL E JONES, 2012), é possível verificar o escopo funcional das ferramentas BPMS. Abaixo é listado este conjunto:

- Integração entre ferramentas BPMS

- Utilização de padrões/formatos e linguagem

- Interface como o usuário

- Base de dados própria

- Geração de relatórios

- Controle de Usuários

- Portal de publicação

- Simulação

- Conectores externos

No relatório IDC MarketScape (MAUREEN FLEMING E SILVERSTEIN, 2011) é apresentado um estudo sobre os fornecedores de soluções BPMS. Utilizando-se de uma estrutura conceitual são comparadas as ofertas, os recursos e as estratégias de produtos e serviços. Essa estrutura também fornece aos compradores destas tecnologias uma avaliação completa dos pontos fortes e fracos dos fornecedores atuais e potenciais.

Revista Produção Online, Florianópolis, SC, v.15, n. 3, p. 886-913, jul./set. 2015. 
Na Figura 5 é possível observar o mercado de soluções BPMS sob a ótica da comparação proposta por Maureen Fleming e Silverstein (2011), anteriormente mencionada.

Figura 5 - MarketScape Business Process Platforms

\section{IDC - Mercado das plataformas de processos de negócios}

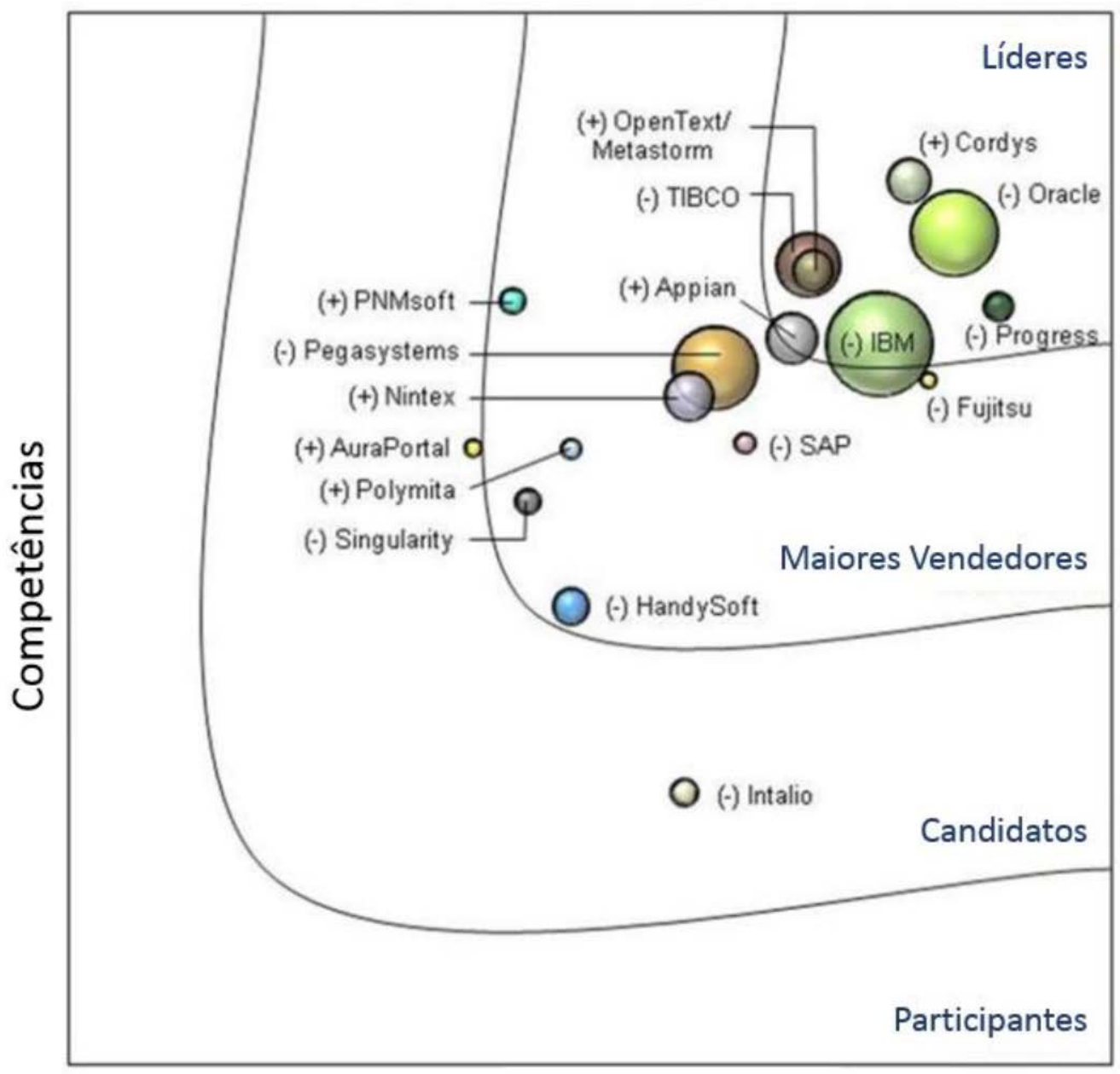

\section{Estratégias}

Fonte: Maureen Fleming e Silverstein (2011)

Como mostrado pela Figura 6, a IBM foi classificada como líder de mercado destas soluções no ano de 2011. Recentemente também foi considerada líder de mercado destas soluções pela consultoria Gartner, em relatório "Magic Quadrant for Intelligent Business Process Management Suites (IBPMS)"(JONES, SCHULTE E CANTARA, 2014). Ver Figura 6. 
Figura 6 - Magic Quadrant for Intelligent Business Process Management Suites (IBPMS)

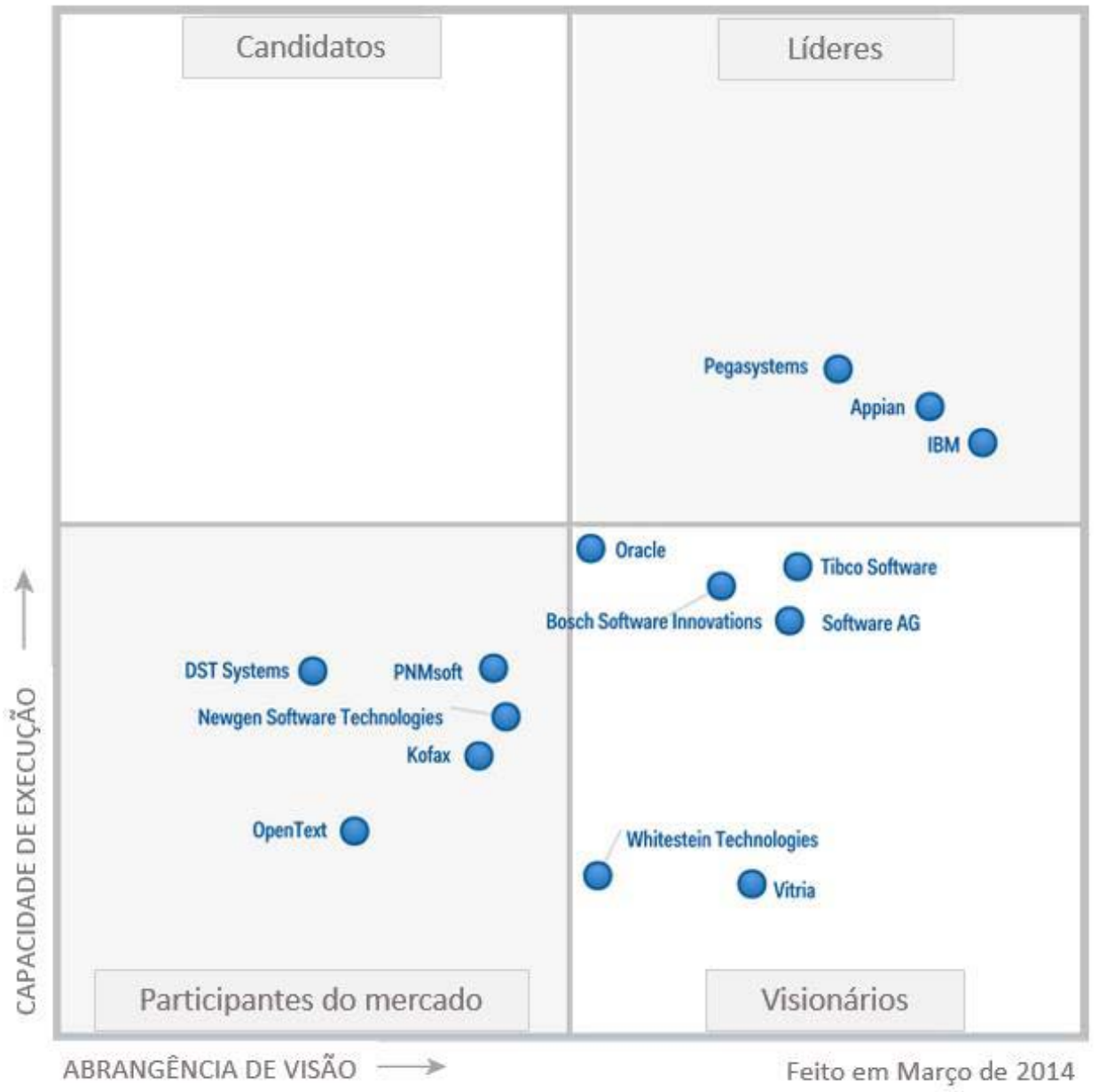

Fonte: Jones, Schulte e Cantara (2014)

Estas soluções BPMS são apontadas por alguns especialistas como a melhor forma de aplicação do BPM em uma organização, superando, inclusive, a utilização de sistemas legados. Porém, acreditamos que a utilização dos BPMS está ligada diretamente com o modelo de negócio ao qual ele será aplicado. É necessário conhecer bem o negócio antes de definir alguma tecnologia de aplicação.

\section{IDENTIFICAÇÃO DOS ELEMENTOS BPM}

A identificação dos elementos BPM foi uma atividade de pesquisa e catalogação. Com o BPM definido pela sessão 1.4 e suas subseções, somado com o estudo do mercado BPM na sessão 1.6, pôde-se identificar quais elementos pertencem e/ou estão ligados ao BPM. Os elementos identificados foram:

- Negócio 
- Melhoria contínua - Ciclo BPM

- Processos de negócio

- Modelagem de processos

- Automação de processos

\subsection{Negócio}

Negócio é uma terminologia utilizada para representar um grupo de atividades orquestradas por um grupo de pessoas, cujo interesse é entregar valor para clientes em troca de um retorno para as partes interessadas (ABPMP, 2014). Normalmente são encontrados em todos os tipos de organizações públicas ou privadas, com ou sem fins lucrativos (ABPMP, 2014; PAVANI JÚNIOR E SCUCUGLIA, 2011).

\subsection{Ciclo BPM}

Na literatura é possível encontrar vários modelos para orientar o BPM. Dentre eles, é notável a atuação de elementos que promovem a melhoria contínua. Para a ABPMP (2014), os processos de negócio devem ser gerenciados em um ciclo contínuo, a fim de manter sua integridade e permitir a transformação.

A abordagem de Ciclo BPM aplicada nesta pesquisa é fruto da prática de implantações de projetos BPM apresentados por Baldam et al. (2007), demonstrados no Quadro 3. Este ciclo tem como objetivo determinar as ligações entre as fases de desenvolvimento de um projeto BPM.

Quadro 3 - Fases do ciclo BPM

\begin{tabular}{|l|l|}
\hline \multicolumn{1}{|c|}{$\begin{array}{c}\text { Fases do ciclo } \\
\text { BPM }\end{array}$} & \multicolumn{1}{c|}{ Descrição } \\
\hline Planejamento & $\begin{array}{l}\text { Está relacionado com a definição de planos de ação para implementação, } \\
\text { definição dos processos que necessitam de ação imediata. }\end{array}$ \\
\hline $\begin{array}{l}\text { Modelagem e } \\
\text { otimização de } \\
\text { processos }\end{array}$ & $\begin{array}{l}\text { Atividades que permitem gerar informaçães sobre o processo atual (As is) } \\
\text { e/ou sobre a proposta de processo futuro (To Be). }\end{array}$ \\
\hline $\begin{array}{l}\text { Execução do } \\
\text { processo }\end{array}$ & Atividades que garantirão a implementação e a execução dos processos. \\
\hline $\begin{array}{l}\text { Controle e análise } \\
\text { de dados }\end{array}$ & $\begin{array}{l}\text { Atividades relacionadas ao controle geral do processo (por meio de diversos } \\
\text { recursos, como o uso de indicadores). Geram informações que } \\
\text { posteriormente realimentarão as atividades de otimização e planejamento. }\end{array}$ \\
\hline
\end{tabular}

Fonte: Adaptado de Baldam et al. (2007) e Sousa et al. (2013) 
Talvez uma das características mais expressivas dos ciclos BPM seja a capacidade de executar múltiplos refinamentos sucessivos, uma vez que no universo BPM a capacidade de evoluir é mais apreciada que a capacidade de criar pela primeira vez (ABPMP, 2014).

\subsection{Processos ne negócio}

Para a compreensão deste elemento, são apresentadas definições referentes aos processos e aos processos de negócio, demonstradas no Quadro 4. O objetivo é construir uma definição própria que reflita um ponto de vista esclarecedor sobre os processos de negócio.

Quadro 4 - Termos e Definições - Processos e Processos de negócio

\begin{tabular}{|c|c|}
\hline Termo & Definição \\
\hline Processos (PLATTS et al., 1996) & $\begin{array}{l}\text { São eventos sequenciados que descrevem modificações ao } \\
\text { longo do tempo, normalmente desenvolvidos de acordo com } \\
\text { um objetivo. }\end{array}$ \\
\hline Processo (JURAN, 1992) & $\begin{array}{l}\text { É uma série sistemática de ações direcionadas para a } \\
\text { consecução de uma meta. A definição genérica aplica-se a } \\
\text { um processo em todas as funções, relacionadas com a } \\
\text { fabricação ou não. Também inclui as forças humanas, assim } \\
\text { como as instalações físicas. }\end{array}$ \\
\hline Processo (D'ACENÇÃO, 2001) & É um conjunto de causas, que provoca um ou mais efeitos. \\
\hline Processo (OLIVEIRA, 2006) & $\begin{array}{l}\text { Um conjunto estruturado de atividades sequenciais que } \\
\text { apresentam relação lógica entre si, com a finalidade de } \\
\text { atender e, preferencialmente, suplantar as necessidades e as } \\
\text { expectativas dos clientes externos e internos da empresa. }\end{array}$ \\
\hline $\begin{array}{lr}\text { Processo } & \text { (ASSOCIAÇÃO } \\
\text { BRASILEIRA DE } & \text { NORMAS } \\
\text { TÉCNICAS, 2008) } & \end{array}$ & $\begin{array}{l}\text { Processos podem ser compreendidos como a transformação } \\
\text { de entradas e saídas. }\end{array}$ \\
\hline $\begin{array}{l}\text { Processo de negócio (ABPMP, } \\
2014 \text { ) }\end{array}$ & $\begin{array}{l}\text { É uma agregação de atividades e componentes executados } \\
\text { por humanos ou máquinas para alcançar um ou mais } \\
\text { resultados. }\end{array}$ \\
\hline $\begin{array}{l}\text { Processo de negócio (ERIKSSON } \\
\text { E PENKER, 2000) }\end{array}$ & $\begin{array}{l}\text { É uma abstração do funcionamento do próprio negócio. É } \\
\text { composto por: objetivos, recursos, processos e regras. }\end{array}$ \\
\hline $\begin{array}{l}\text { Processos de Negócio (OMG, } \\
\text { 2011) }\end{array}$ & $\begin{array}{l}\text { É qualquer atividade executada dentro de uma companhia ou } \\
\text { organização. }\end{array}$ \\
\hline
\end{tabular}

Fonte: O autor (2014)

Com as definições apresentadas anteriormente foi possível induzir que:

Os processos de negócio são uma representação do funcionamento de um negócio, orientado por um modelo sistêmico composto por processos, eventos, atividades e tarefas, cujo objetivo é organizar o fluxo e as operações de troca de valores entre fornecedores e clientes.

No Boxe 1 são apresentados alguns elementos que compõem os processos de negócio, conjunto que não se limita a estes onze elementos, mas acredita-se que Revista Produção Online, Florianópolis, SC, v.15, n. 3, p. 886-913, jul./set. 2015. 
seja um grupo que proporciona um entendimento abrangente sobre os processos de negócio.

Boxe 1 - Elementos BPM

a) Macroprocesso: É um termo aplicado a processos que acionam outros processos, ou seja, dentro da estrutura organizacional, os macroprocessos são os processos de interface (PAVANI JÚNIOR E SCUCUGLIA, 2011) que dão início aos subprocessos. Essa terminologia é utilizada para classificar os processos que utilizam-se de outros como atividades em seu fluxo de valor. De forma sucinta, macroprocesso é um processo que inclui a execução de outro (CAMPOS, 2013).

b) Subprocesso: É um termo aplicado a processos que são acionados por outros, esse, por sua vez, é considerado um macroprocesso de seu subprocesso (CAMPOS, 2013). Um subprocesso é um processo que está incluso em forma de atividade em um outro processo (BALDAM et al., 2007).

c) Evento: São os acontecimentos no curso de um processo de negócio. Podem ser considerados como gatilhos de disparo para processos e atividades (ABPMP, 2014). Existem três grupos de eventos: eventos de início, eventos de termino e eventos intermediários. Todos eles influenciam diretamente no fluxo de um processo (VALLE E COSTA, 2009).

d) Atividade: É um termo genérico que representa o trabalho que uma organização executa através de um processo de negócio (PAIM et al., 2009). Ela é constituída de um conjunto de tarefas que pode ser executado por uma ou mais pessoas. Muitas vezes interpretadas como fichas de tarefas por compreender "um agrupamento de uma série de tarefas, similares e/ou complementares [...]" (SOUSA et al., 2013). Seu enfoque é 'o que fazer', como pré-requisito indispensável para a consecução do um objetivo (PAVANI JÚNIOR E SCUCUGLIA, 2011). Subprocessos, processos e tarefas, são tipos de atividades (BALDAM et al., 2007; VALLE E COSTA, 2009). Segundo a norma BPMN 2.0 (OMG, 2011), as atividades podem ser classificadas como: Humanas, Abstratas ou De Serviço.

e) Tarefa: Uma tarefa é entendida como o meio pelo qual é operacionalizada uma atividade, é uma ação explicitamente definida (CRUZ, 2010). Tarefas são os elementos da sequência de passos/etapas pré-determinados para se realizar uma atividade. Cada um desses passos pode demandar a necessidade de explicação detalhada de 'como fazer' (PAVANI JÚNIOR E SCUCUGLIA, 2011). As tarefas são consideradas a menor instância de trabalho de uma atividade (ABPMP, 2014; PAVANI JÚNIOR E SCUCUGLIA, 2011).

f) Formulário: É um termo aplicado a um conjunto de tarefas agrupadas dentro de uma atividade. De modo que uma atividade pode conter " $n$ " formulários.

g) Cenário: É um termo utilizado para representar a composição de uma tarefa, de modo a indicar as suas modalidades de execução. Por exemplo, a tarefa "comunicar ao cliente" pode ser realizada por meio de distintos cenários: por e-mail, por telefone ou pessoalmente. Cada um desses irá gerar uma execução, um passo diferente (ABPMP, 2014).

h) Passo: "Na decomposição de tarefas em um determinado cenário, passo indica a ação em nível atômico necessária para executar o trabalho" (ABPMP, 2014).

i) Instância: Segundo o guia CBOK, "Instância de processo é cada execução do processo" (ABPMP, 2014). Logo, todas as execuções de um processo geram instâncias.

j) Caso: O caso é uma instância de um processo. Porém, diferente de uma instância comum, o caso tem como característica produzir e entregar um resultado exclusivo (ABPMP, 2014)

k) Atores: São as pessoas, cargos ou funções que executam as atividades (Campos, 2013). Podem ser colaboradores, gestores, fornecedores, clientes ou sistemas que contribuem diretamente para a realização das atividades contidas no fluxo do processo. Eles possuem a capacidade de discernir entre "O QUE, ONDE, QUANDO, POR QUE, COMO e POR QUEM fazer" (ABPMP, 2014).

Fonte: O autor (2014) 
Os processos de negócio podem ser a grande chave para o sucesso de uma organização. Sabe-se que, independentemente da linguagem de representação destas estruturas, sua utilização possibilita grandes vantagens competitivas (ABPMP, 2014).

\subsection{Modelagem de processos de negócio}

Para a ABPMP (2014), a modelagem de processos de negócio é o conjunto de atividades envolvidas na criação de processos completos e precisos sobre o funcionamento de um negócio. No desenvolvimento desta modelagem, são requeridas habilidades e técnicas para compreender, gerenciar e comunicar os negócios. Ela cria modelos sobre rotinas de atividades observadas na realidade. $O$ papel dos atores é fundamental para o desenvolvimento de um processo que represente, de fato, a realidade operacional de um negócio (CAMPOS, 2013; PENG, SCHROEDER E SHAH, 2012; PIDD, 1996).

Segundo Campos (2013) por meio do trabalho de modelagem de processos "é possível que as organizações melhorem seus processos, ganhem eficiência, flexibilidade e vantagens competitivas...".

Para compreender melhor as atividades de modelagem, foram realizadas pesquisas sobre: Modelo, Notação para modelagem, Notação BPMN e Desenho do Processo. Elas estão apresentadas no Boxe 2.

Boxe 2 - Elementos BPM

(continua)

a) Modelo: É uma representação da realidade (ACKOFF E SASIENI, 1968). Perante esta definição e outras, o pesquisador M. Pidd afirma que: "Um modelo é uma representação externa e explícita de parte da realidade vista pela pessoa que deseja usar aquele modelo para entender, mudar, gerenciar e controlar parte daquela realidade" (PIDD, 1996). No Quadro 8 é possível observar uma comparação entre o modelo perante a realidade.

Quadro 1 - Realidade versus Modelo.

\begin{tabular}{|c|c|}
\hline Realidade & Modelo \\
\hline Complexa & Simples \\
\hline Delicada & Concreto \\
\hline Mal definida & Totalmente definido \\
\hline
\end{tabular}

Fonte: Pidd (1996)

Ao analisar o Quadro 5 juntamente com a definição apresentada por Pidd (1996), conclui-se que a realidade não é uma só para todos. Diferente dos modelos, a realidade é individual, podendo haver uma concepção diferente da mesma realidade de um indivíduo para outro. Isso deve-se ao fato dela ser complexa, logo, quando lida é polarizada pelo filtro do leitor. 
Os modelos de negócio são leituras explícitas sobre a realidade operacional de um negócio. Da mesma forma que a realidade, os modelos podem ser interpretados e compreendidos de maneira parcial, ocasionando mau entendimento do negócio. Por isso, o modelo de um negócio deve ser formalmente detalhado e auto-explicativo (ABPMP, 2014).

b) Notação para modelagem de processos: Segundo Campos (2013), a notação pode ser comparada a uma linguagem, possuindo um sistema bem definido, com padrões e regras. Existem diversas formas de representar processos, historicamente o que pode ser considerada como a primeira notação é a representação de workflow, conhecida como Fluxograma (CAMPOS, 2013).

A escolha de uma notação deve considerar os níveis do processo e as especificidades da organização, desta forma, é possível que um processo seja representado por diferentes notações para diferentes finalidades ou níveis de maturidade (ABPMP, 2014).

No Quadro 9, retirado do Guia BPM CBOK, são apresentas diferentes notações de representação de processos de negócio.

Quadro 2 - Notações para modelagem de processos de negócio.

Notações para modelagem de processos de negócio

BPMN (Business Process Model and Notation)

Fluxograma

EPC (Event-driven Process Chain)

UML (Unified Modeling Language)

IDEF (Integrated Definition Language)

Value Stream Mapping

Fonte: Adaptado de (ABPMP, 2014).

c) Notação BPMN: Atualmente, o BPMN - Business Process Modeling Notation é a notação mais utilizada para modelagem de Processos de Negócio (ABPMP, 2014; CAMPOS, 2013). O grupo BPMI - Business Process Management Iniciative, em 2002, deu início ao desenvolvimento desta notação gráfica de representação de processos. Em 2006, a organização internacional OMG - Object Management Group, fundada para apoiar a construção de padrões, se responsabilizou pela manutenção desta notação (OMG, 2011).

Campos (2013) atribui o sucesso da notação BPMN ao fato de ela ter sido desenvolvida com o objetivo principal de ser facilmente entendida por pessoas, de modo a facilitar a visualização e compreensão dos processos modelados por ela criados. ABPMP (2014) coloca que a aceitação desta notação tem crescido sobre várias perspectivas, sendo uma delas o fato de estar presente em várias ferramentas de modelagem de processo. Esta notação apresenta um conjunto robusto de símbolos para modelagem de diferentes aspectos de processos.

Atualmente, a notação encontra-se na sua versão 2.0, onde foram adicionadas novas opções de representação de eventos específicos. Assim como o UML, a notação BPMN independe de fornecedores e pode ser utilizada como elemento de integração entre plataformas de diferentes fabricantes (HARRISON, 1998; OMG, 2011).

d) Desenho do processo: $O$ desenho do processo deve compreender e prever a flexibilidade da operação, possibilitando a aplicação de expertises e qualidades dos atores envolvidos durante a execução das atividades (ABPMP, 2014).

Logo, o desenho de um processo é uma atividade de identificação e mapeamento dos resultados esperados para uma operação (CAPOTE, 2011).

Com ele, as pessoas seguem um método que é suportado por ferramentas tecnológicas para gerar um resultado. Bons processos constituem-se de métodos otimizados, pessoas preparadas e tecnologia apropriada (ABPMP, 2014).

Fonte: O autor (2014) 
A modelagem de processos pode compreender muito mais do que apenas 0 fluxo de valores entre clientes e fornecedores. Para alguns profissionais da área é a grande oportunidade para proporcionar a evolução da cultura de uma organização (PAVANI JÚNIOR E SCUCUGLIA, 2011).

\subsection{Automação de processos}

Em busca de eficiência operacional, as organizações estão automatizando cada vez mais seus processos. A automação pode ocorrer pela implantação de ferramentas de workflow ou pela escolha de sistemas específicos para as suas necessidades. Independentemente da forma de automação escolhida, o objetivo é tornar os processos mais eficientes e robustos, suportando uma carga de trabalho maior. Porém, se os processos são ruins e confusos, os sistemas de informação construídos a partir deles não serão melhores. É comum que organizações culpem as áreas de TI pelo fracasso da automação de processos imaturos (CAMPOS, 2013; ELRAGAL E HADDARA, 2012).

As ferramentas de workflow são, em sua maioria, soluções BPMS, que são suítes especializados para o desenvolvimento, gerenciamento e otimização de processos. Normalmente são softwares que associam paletas de recursos gráficos com scripts de programação no formato de linhas de código. Essas ferramentas tomaram destaque rapidamente dentro das organizações, devido à constatação de seus benefícios a curto e longo prazo (ABPMP, 2014; GOU et al., 2003).

Os sistemas de automação de processos podem ser soluções desenvolvidas especificamente para o atendimento de uma necessidade organizacional ou pode-se adotar ferramentas prontas no mercado.

\section{FRAMEWORK CONCEITUAL DE INTERLIGAÇÃO DOS ELEMENTOS BPM}

Os estudos sobre o BPM e os BPMS apresentados, possibilitaram 0 levantamento dos elementos BPM e a identificação de suas interligações. A partir disso, foi desenvolvido o framework representado pela Figura 7.

No framework, os conhecimentos BPM são posicionados dentro da estrutura organizacional de um negócio. Dessa forma, é possível identificar como pode ser 
exercida a gestão BPM. Acredita-se que o BPM apresenta relação direta com gestão estratégica de operações e com a gestão estratégica por desempenho.

Figura 1 - Framework conceitual de interligação dos elementos BPM

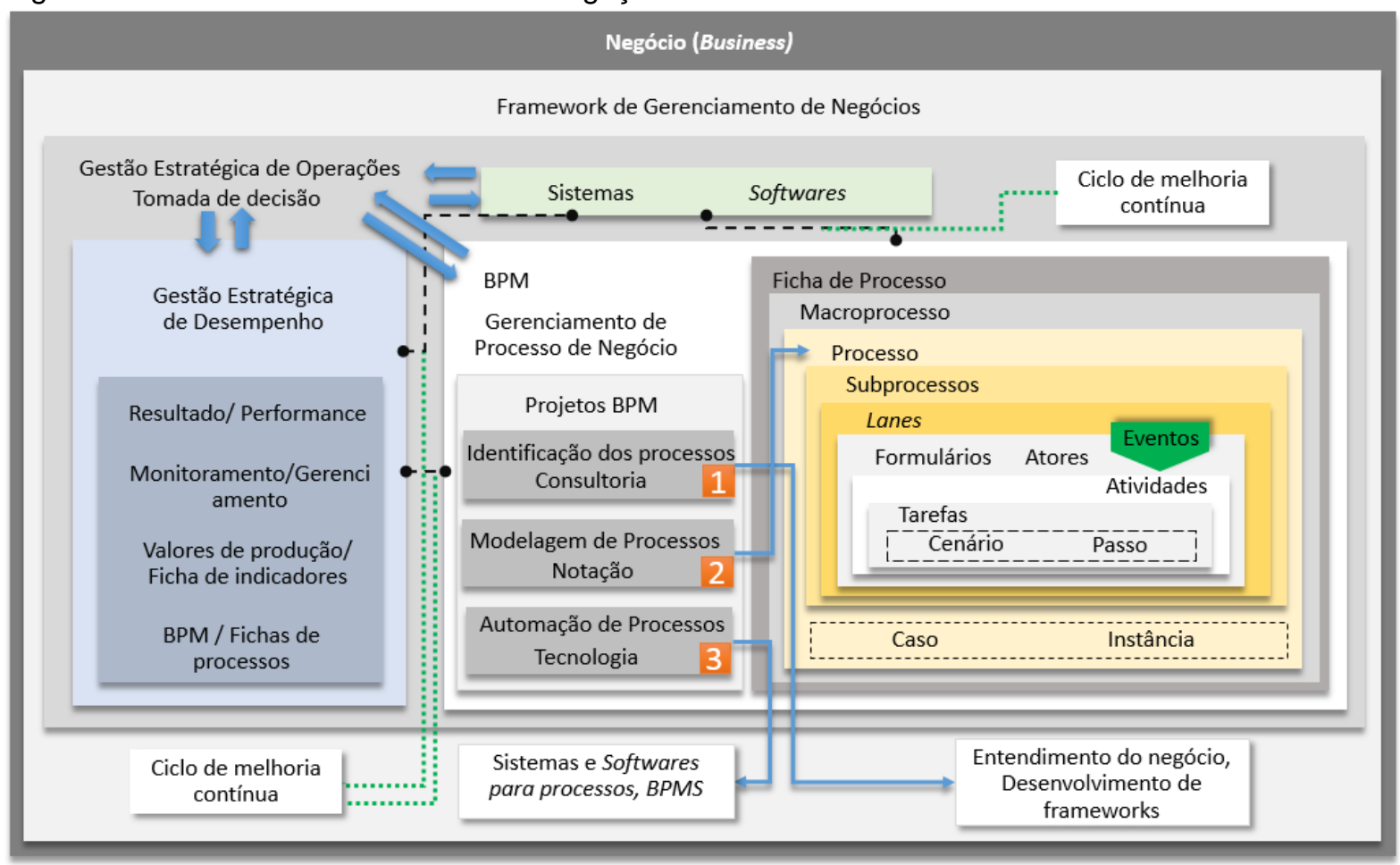

Fonte: O autor (2014)

O framework está organizado conforme a visão da estrutura gerencial de um negócio, ou seja, os elementos foram dispostos de maneira a compor uma visão operacional do gerenciamento de um negócio. Desta forma, é possível observar a atuação de cada elemento BPM.

Neste framework, a Gestão Estratégica de Operações - GEO é o maior nível de execução do gerenciamento. De certa forma, ela organiza e orienta todos os atos operacionais envolvidos no negócio. São observados três grupos que atuam sob seu domínio, são eles: Gestão estratégica de Desempenho; BPM e Sistemas e Softwares. Em cada um deles é observada uma relação multidimensional de interligação. Uma camada de comunicação direta com a GEO, outra de troca de informações entre os grupos e uma camada de comunicação via bases de dados.

Gestão estratégica de desempenho - GED tem como objetivo controlar os resultados de um negócio por meio de análises e avalição da performance operacional. Um dos recursos utilizados por esta gestão é o monitoramento de indicadores de desempenho, de forma que os valores monitorados podem ser Revista Produção Online, Florianópolis, SC, v.15, n. 3, p. 886-913, jul./set. 2015. 
derivados diretamente dos processos BPM e de outros mecanismos de produção (Choong, 2013).

Gerenciamento de processos de negócio - BPM é representado por meio da aplicação de projetos BPM, na qual pode-se observar a divisão em três etapas. A etapa 1, consultoria - é aplicada na identificação dos processos e no entendimento do negócio. A etapa 2 trata da modelagem dos processos BPM, onde observa-se a disposição de seus elementos: ficha do processo, macroprocessos, processos, subprocesso, caso, instância, Lanes, formulários, atores, atividades, eventos, tarefas, passos e cenário. A etapa 3 é considerada a etapa de tecnologia, na qual é realizada a automação de processos, apresentando como resultado a aplicação de soluções BPMS e/ou uso de sistemas.

Sistemas e Softwares - este grupo é composto por soluções específicas de controle operacional. De certa forma, são ferramentas que colaboram com a GEO, fornecendo informações para a tomada de decisões.

\section{CONSIDERAÇÕES FINAIS}

Propoen-se que a para identificação dos processos pode-se utilizar o Process Approach, que é uma método de desenvolvimento de processos de operacionalização de frameworks conceituais, cuja aplicação trata do desenvolvimento de um processo constituído de etapas, fases e passos operacionalizados por folhas de tarefa (FT), respeitando as características desejáveis dos processos (PINHEIRO DE LIMA E GOUVEA DA COSTA, 2012; PLATTS E GREGORY, 1990; PLATTS, 1993).

Outro ponto importante a ser adicionado a esse estudo, são os recursos de Business intelligence, quando utilizados como ferramentas integradas à GED, é possível supervisionar indicadores de desempenho, criando assim, subsídios que orientam a tomada de decisão por parte da GEO, dete modo comungando com as idéias apresnetadas em CHOONG (2013).

Raciocínio baseado em casos é uma técnica de inteligência artificial que tem como objetivo solucionar situações atuais através da recuperação e adaptação de soluções semelhantes ocorridas no passado (RIESBECK E SCHANK, 1989). Essa técnica é utilizada em todos os grupos de gerenciamento, uma vez que para auxiliar 
uma tomada de decisão futura são utilizados fatos já ocorridos como parâmetros de avaliação (KOLODNER, 1997). Com isso é promovida a evolução do negócio, garantindo a sustentabilidade operacional.

\section{CONCLUSÃo}

Ao propor o framework conceitual de interligação dos elementos BPM - Figura 7, busca-se representar de forma gráica uma estrutura para posicionamento do BPM dentro de um modelo de gestão. Conforme proposto, este recurço participa diretamente das relações multidimencionais entre os grupos de gerenciamento: Gestão Estratégica de Desempenho e Gestão Estratégica de Operaçãoes.

Um ponto importante é a estrutura organizacional utilizada na representação de um negócio na Figura 7. Ao passo que observa-se uma robusta estrutra de suporte a gestão para a tomada de decisão, podese diser que aplica-se o BPM para controlar e supervisionar as operações, por meio de processos e tecnologias derivadas deste conjunto de praticas.

Com esta pesquisa é possível afirmar que, os resultados da aplicação do BPM não se limitam à busca do aumento de eficiência operacional, podendo também ser considerado elemento chave de suporte à gestão organizacional, proporcionando uma mudança na cultura organizacional e estruturando as operações.

\section{REFERÊNCIAS}

ABPMP. BPM CBOK ${ }^{\mathrm{TM}}$ V3.0. guide to the business process management common body of knowledge. 2. ed. Brasil: Association of Businees Process Management Professsionals Brasil, 2014.

ABPMP Brasil. Disponível em: <http://www.abpmp-br.org/>. Acesso em: 22 maio. 2014. ACKOFF, R. L.; SASIENI, M. W. Fundamental of operations research. Michigan: Jhon Whiley and Sons Inc., 1968.

ALBUQUERQUE, J. P. DE. Flexibilidade e modelagem de processos de negócio: uma relação multdimencionaL. RAE - Revista de Administração de Empresas, v. 52, n. 3, p. 313-329, 2012.

AL-TABBAA, O.; GADD, K.; ANKRAH, S. Excellence models in the non-profit context: strategies for continuous improvement. International Journal of Quality \& Reliability Management, v. 30, n. 5, p. 590-612, 2013. http://dx.doi.org/10.1108/02656711311315521 
ASSOCIAÇÃO BRASILEIRA DE NORMAS TÉCNICAS. NBR ISO 9001:2008. 2. ed. [s.I.] ABNT - Associação Brasileira de Normas Técnicas, 2008.

BALDAM, R. DE L. et al. Gerenciamento de processos de negócio: BPM - business process management. 2. ed. São Paulo: Editora Érica, 2007.

BONITASOFT - Open source workflow \& BPM software. Disponível em: $<$ http://www.bonitasoft.com/>. Acesso em: 22 maio. 2014.

CAMPOS, A. L. N. Modelagem de processos com BPMN. Rio de Janeiro: Brasport Livros e Multmídia, 2013.

CAPOTE, G. BPM para todos. Rio de Janeiro: Bookess, 2011.

CHOONG, K. K. Are PMS meeting the measurement needs of BPM? A literature review. Business Process Management Journal,, v. 19, n. 3, p. 535-574, 2013.

CLARK, K. B.; WHEELWRITHG, S. C. Organizing and leading "heavywheight" development Teams. Califormnia Management Reviewnia, 1992.

CRUZ, T. BPM \& BPMS: business process management \& business process management systems. 2. ed. Rio de Janeiro: Brasport Livros e Multmídia, 2010.

BPMS e seu ciclo de vida. In: Análise e Modelagem de Processos de Negócio: Foco na Notação BPMN (Businees Process Modeling Notation). 1. ed. São Paulo - SP: Editora Atlas, 2013. p. 148-160.

D'ACENÇÃO, L. C. M. Organização, sistema e método: análise, desenho e informatização de processos administrativo. 1. ed. São Paulo - SP: Editora Atlas, 2001.

DAMELIO, R. The Basics of process maping. 2. ed. USA: CRC Press, Taylo r\& Francis Group, 2011.

ELRAGAL, A.; HADDARA, M. The Future of ERP Systems: look backward before moving forward. Procedia Technology, v. 5, p. 21-30, 2012.

ERIKSSON, H.-E.; PENKER, M. Business modeling with uml: business patterns at Work. 1. ed. USA: OMG PRESS, 2000.

FREUND, J.; RÜCKER, B. REAL-LIFE BPMN: using bpmn 2.0 to analysze, improve, and automate processos in your company. 1. ed. James Venis of Lakewood, Colorado, USA: Camunda, 2012.

GMELIN, H.; SEURING, S. Achieving sustainable new product development by integrating product life-cycle management capabilities. International Journal of Production Economics, v. 154, p. 166-177, 2014.

GONÇALVES, J. E. L. As empresas são grandes coleções de processos. RAE - Revista de Administração de Empresas, v. 40, n. 1, p. 6-19, 2000.

GOU, H. et al. A framework for virtual enterprise operation management. Computers in Industry, v. 50, n. 3, p. 333-352, 2003.http://dx.doi.org/10.1016/S0166-3615(03)00021-6 
HARRISON, A. Investigating business processes: does process simplification always work? Business Process Management Journal, v. 4, n. 2, p. 1337-153, 1998.

JONES, T.; SCHULTE, W. R.; CANTARA, M. Magic Quadrant for Intelligent Business Process Management SuitesGartner, , 2014. Disponível em: http://www.gartner.com/technology/reprints.do?id=1-1QZPW94\&ct=140220\&st=sb

JURAN, J. M. Juran Planejando para a qualidade. 2. ed. São Paulo - SP: Editora e livraria Pioneira, 1992.

KOLODNER, J. L. Educational implications of analogy: A view from case-based reasoning. American Psychologist, v. 52, n. 1, p. 57-66, 1997.

MALAMUT, G. Processos Aplicados a Sistema Integrados de Gestão $1^{\circ}$ Seminário Brasileiro de Gestão de Processos. Anais...Rio de Janeiro: SAGE-COPPE-UFRJ, 2005.

MAUREEN FLEMING; SILVERSTEIN, J. IDC MarketScape: Worldwide Business Process Platforms 2011 Vendor Analysis. [s.I: s.n.]

MELÃO, N.; PIDD, M. A conceptual framework for understanding business processes and business process modelling. Information Systems Journal, v. 10, n. 2, p. 105-129, 2000.

NADARAJAH, D.; KADIR, S. L. S. A. A review of the importance of business process management in achieving sustainable competitive advantage. The TQM Journal, v. 26, n. 5, p. 522-531, 2014. http://dx.doi.org/10.1108/TQM-01-2013-0008

OLIVEIRA, D. DE P. R. DE. Administração de processos: conceitos, metodologia e práticas. São Paulo - SP: Editora Atlas, 2006.

OMG, O. M. G. Business process model and notation (BPMN)OMG, , 2011. Disponível em: http://www.omg.org/spec/BPMN/2.0

PAIM, R. et al. Gestão de processos: pensar agir e aprender. Porto Alegre: Bookman, 2009.

PALVARINI, B.; QUEZADO, C. Gestão de processos voltada para resultado. 1. ed. [s.I.] Vertsys, 2013.

PAVANI JÚNIOR, O.; SCUCUGLIA, R. Mapeamento e gestão por processos - BPM: gestão orientada à entraga por meio de objetos: metodologia GRAUSS. São Paulo - SP: M. Books do Brasil Ltda., 2011.

PENG, D. X.; SCHROEDER, R. G.; SHAH, R. Linking routines to operations capabilities: A new perspective. Journal of Operations Management, v. 26, n. 6, p. 730-748, 2012.

PIDD, M. Modelagem empresarial - ferramentas para tomada de decisao. [s.I.] Bookman, 1996.

PINHEIRO DE LIMA, E.; GOUVÊA DA COSTA, S. E. Processos: Uma Abordagem da Engenharia de Operações. In: metodologia de pesquisa em engenharia de produção e gestão de operações. 2. ed. São Paulo - SP: [s.n.]. p. 199-216.

PLATTS, K. W. A process approach to researching manufacturing strategy. International Journal of Operations \& Production Management, v. 13, n. 8, p. 4-17, 1993. 
Evaluating manufacturing strategy formulation processes. International Journal of Production Economics, v. 46-47, p. 233-240, 1996.

http://dx.doi.org/10.1016/0925-5273(95)00029-1

PLATTS, K. W.; GREGORY, M. Manufacturing audit in the process of strategy formulation. international journal of operations \& production Management, v. 10, n. 9, p. 5-26, 1990.

PMI. Um guia do conhecimento em gerenciamento de projetos (guia PMBOK). 4. ed. Newtown Square, Pennsylvania EUA: Project Management Isntitute, Inc., 2008.

RIESBECK, C. K.; SCHANK, R. C. Imside case-based reasoning. Hillsdale, New Jersey USA: Lawrence Erlbaum Associates, 1989.

SANTOS ROCHA, R. DOS; FANTINATO, M. The use of software product lines for business process management: a systematic literature review. Information and Software Technology, v. 55, n. 8, p. 1355-1373, ago. 2013. http://dx.doi.org/10.1016/j.infsof.2013.02.007

SCHULTE, W. R.; HILL, J. B.; JONES, T. Magic quadrant for intelligent business process management suites. [s.l: s.n.].

SELTSIKAS, P. Information management in process-based organizations: a case study at Xerox Ltd. Information Systems Journal, v. 9, n. 3, p. 181-195, 1999.

SOUSA, A. C. M. E et al. Análise e modelagem de processos de negócio: foco na notação BPMN (Business Process Modeling Notation). 1. ed. São Paulo: Editora Atlas, 2013.

VALLE, R.; COSTA, M. M. Gerenciar os processos, para agregar valor à organização. In: Análise e modelagem de processos de negócio: foco na notação BPMN (Businees Process Modeling Notation). 1. ed. São Paulo - SP: Editora Atlas, 2009. p. 1-14.

ZANGISKI, M. A. DA S. G.; PINHEIRO DE LIMA, E.; GOUVÊA DA COSTA, S. E. Organizational competence building and development: Contributions to operations management. International Journal of Production Economics, v. 144, n. 1, p. 76-89, 2013. http://dx.doi.org/10.1016/j.ijpe.2013.01.021

SANTOS ROCHA, R. DOS; FANTINATO, M. The use of software product lines for business process management: a systematic literature review. Information and Software Technology, v. 55, n. 8, p. 1355-1373, ago. 2013.

http://dx.doi.org/10.1016/j.infsof.2013.02.007

\section{SCHULTE, W. R.; HILL, J. B.; JONES, T. Magic quadrant for intelligent business process management suites. [s.l: s.n.].}

SELTSIKAS, P. Information management in process-based organizations: a case study at Xerox Ltd. Information Systems Journal, v. 9, n. 3, p. 181-195, 1999.

SOUSA, A. C. M. E et al. Análise e modelagem de processos de negócio: foco na notação BPMN (Business Process Modeling Notation). 1. ed. São Paulo: Editora Atlas, 2013.

VALLE, R.; COSTA, M. M. Gerenciar os processos, para agregar valor à organização. In: Análise e modelagem de processos de negócio: foco na notação BPMN (Businees Process Modeling Notation). 1. ed. São Paulo - SP: Editora Atlas, 2009. p. 1-14. 
ZANGISKI, M. A. DA S. G.; PINHEIRO DE LIMA, E.; GOUVÊA DA COSTA, S. E. Organizational competence building and development: Contributions to operations management. International Journal of Production Economics, v. 144, n. 1, p. 76-89, 2013. http://dx.doi.org/10.1016/j.ijpe.2013.01.021

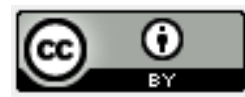

Artigo recebido em 19/02/2014 e aceito para publicação em 17/06/2015.

DOI: http://dx.doi.org/ 10.14488/1676-1901.v15i3.1867 